\title{
Continuous preparation of flavour-active acetate esters by direct biocatalytic esterification
}

Running title: Continuous preparation of flavour esters

Igor Chiarelli Perdomo ${ }^{1}$, Martina Letizia Contente ${ }^{2}$, Andrea Pinto ${ }^{1}$, Diego Romano ${ }^{1}$, Pedro Fernandes ${ }^{3,4}$, Francesco Molinari ${ }^{1}$

${ }^{1}$ Department of Food, Environmental and Nutritional Sciences (DeFENS), University of Milan, via Mangiagalli 25, 20133 Milano, Italy.

${ }^{2}$ School of Chemistry, University of Nottingham, University Park, Nottingham, NG7 2RD, UK.

${ }^{3}$ Department of Bioengineering and IBB Institute for Bioengineering and Biosciences, Instituto Superior Técnico, Universidade de Lisboa, Av. Rovisco Pais, 1049-001 Lisboa, Portugal.

${ }^{4}$ Faculty of Engineering, Universidade Lusófona de Humanidades e Tecnologias, Av. Campo Grande 376, 1749-024 Lisboa, Portugal. 


\section{ABSTRACT}

Mycelium-bound lipase of dry mycelium of Aspergillus oryzae catalysed direct esterification of alcohols and acetic acid in organic solvent, showing high stability towards substrates and products. Water produced during the esterification did not significantly affect the equilibrium of the reaction, allowing for high conversions. These features were exploited for preparing flavour-active acetate esters (e.g., isoamyl and cinnamyl acetate) in batch and continuous systems. A continuous stirred tank membrane reactor (CST-MR) was developed securing good reactor productivity and high biocatalyst stability.

\section{KEYWORDS}

Flavour esters, enzymatic acetylation, biocatalysis, Aspergillus oryzae, continuous reactor

\section{INTRODUCTION}

Many acetate esters of primary alcohols are components of natural flavours and are used as flavor and fragrance agents. ${ }^{1}$ They can be obtained by extraction from natural sources or by enzymatic preparation starting from naturally occurring substrates (e.g., alcohols, carboxylic acids), thus ensuring the definition of "natural". Lipase-catalysed transesterification (or interesterification) in organic solvents or in solvent-free environments is one of the most common enzymatic method for the obtainment of acetate esters. ${ }^{2.4}$ Alternatively, interesterification in water can be efficiently catalysed by specific acyltransferase (e.g., the one from Mycobacterium smegmatis, MsAcT), furnishing excellent yields of different flavour esters. ${ }^{5-7}$

Direct esterification with acetic acid is a preferred option since acetic acid is largely available as natural molecule, but the biotransformation is often hampered by formation of water, which affects the equilibrium of the reaction, thus limiting the final conversion in the desired esters. $^{8-10}$ A large-scale enzymatic production of low molecular weight flavour esters in organic solvent was developed, where solutions for the elimination of substrate and product inhibitions are presented; water produced during the process was continuously removed by azeotropic distillation or by using molecular sieves, hence enabling high yields of the produced esters. ${ }^{11}$ Another major drawback of direct acetylation is the deactivation of lipases in the presence of free acetic acid. ${ }^{12}$ Immobilization of lipases has proven an effective method for stabilizing lipases in the presence of acetic acid. ${ }^{13-20}$ Novozym 435 (the commercial preparation of lipase B from Candida antarctica, CALB, immobilized on a 
macroporous acrylic resin) has been often used as stable and efficient biocatalyst for acetate esters preparation. ${ }^{15,18}$

On the way to improve the performance of lipases for the production of flavour esters, continuous bioreactors can be set up with decisive advantages in terms of productivity and intensification. The final bioreactor productivity depends on the activity and stability of the biocatalyst, whereas molar conversion can be modulated by applying the appropriate residence time in the bioreactor. Towards the development of a continuous methodology, different type of reactors can be set up for the production of esters by direct esterification catalysed by lipases in organic solvents. ${ }^{21,22}$ Continuous stirred tank membrane reactor (CST-MR) have been scarcely used for the continuous enzymatic synthesis of esters, albeit they may offer several advantages (enhanced mass transfer, improved liquid mixing, and reduced clogging) over packed bed reactors. ${ }^{23-26}$ Moreover, the use of a suited membrane allows for continuous removal of the organic liquid phase containing the product, while retaining the biocatalyst inside the reactor. ${ }^{27}$

Mycelium-bound fungal carboxylesterases have been often used for flavor ester production by direct esterification. ${ }^{28}$ Dry mycelium of moulds (e.g. Aspergillus oryzae) can be effectively used for different biotransformations, ${ }^{29,30}$ including direct esterification of different alcohols with remarkable advantages, such as: easy preparation of the biocatalyst, high stability in organic solvents, and high resistance to the inactivation caused by carboxylic acids (including acetic acid); moreover, this biocatalyst favours direct esterification with high molar conversions, enabled by favourable water partition. ${ }^{31-33}$

In this work, we have investigated the continuous preparation of flavour-active acetate esters (isoamyl, and cinnamyl) using mycelium-bound lipase from Aspergillus oryzae in a continuous stirred tank membrane reactor (CST-MR).

2 MATERIALS AND Methods

\subsection{Chemicals and biocatalyst}

All chemicals were purchased from Sigma-Aldrich and were used without any further purification. Aspergillus oryzae $\mathrm{MIM}^{32}$ (Microbiologia Industriale Milano) was cultured in 500 $\mathrm{mL}$ Erlenmeyer flasks containing $125 \mathrm{~mL}$ of liquid medium (Tween $800.5 \% \mathrm{v} / \mathrm{v}$, yeast extract $\left.1 \mathrm{~g} / \mathrm{L},(\mathrm{NH} 4)_{2} \mathrm{SO}_{4} 5 \mathrm{~g} / \mathrm{L}, \mathrm{K}_{2} \mathrm{HPO}_{4} 1 \mathrm{~g} / \mathrm{L}, \mathrm{MgSO}_{4} \cdot 7 \mathrm{H}_{2} \mathrm{O} 0.2 \mathrm{~g} / \mathrm{L}, \mathrm{pH} 5.8\right)$ for $48 \mathrm{~h}$ at $28{ }^{\circ} \mathrm{C}$ on a reciprocal shaker (100 rpm). The mycelium suspension was recovered by vacuum filtration using a Buchner funnel and paper filter and washed with distilled water, and lyophilized. 


\subsection{Batch biotransformations}

Different amounts of dry (lyophilized) mycelium of $A$. oryzae were suspended in $2.5 \mathrm{~mL}$ of $\mathrm{n}$-heptane for 30 minutes and the reactions started by adding different concentrations of isoamyl alcohol and acetic acid; the reaction mixture was maintained at the desired temperature under magnetic stirring. Samples $(0.25 \mathrm{ml})$ were taken at intervals, added to an equal volume of an internal standard solution ( $n$-octanol) in $n$-heptane and analyzed by GC.

\subsection{Continuous reaction procedure}

The vessel used in this study was a glass-made membrane reactor constructed by the glass workshop of University of Milan. The working volume of the reactor was $200 \mathrm{~mL}$ (a picture and a cross section of the membrane reactor are given in Fig. 2. The membrane bioreactor was composed with a thermostated water-jacketed glass vessel and an ultrafiltration module $(0.1 . \mu \mathrm{m})$ mounted on the bottle cap. Fluidification was maintained using a magnetic stirrer.
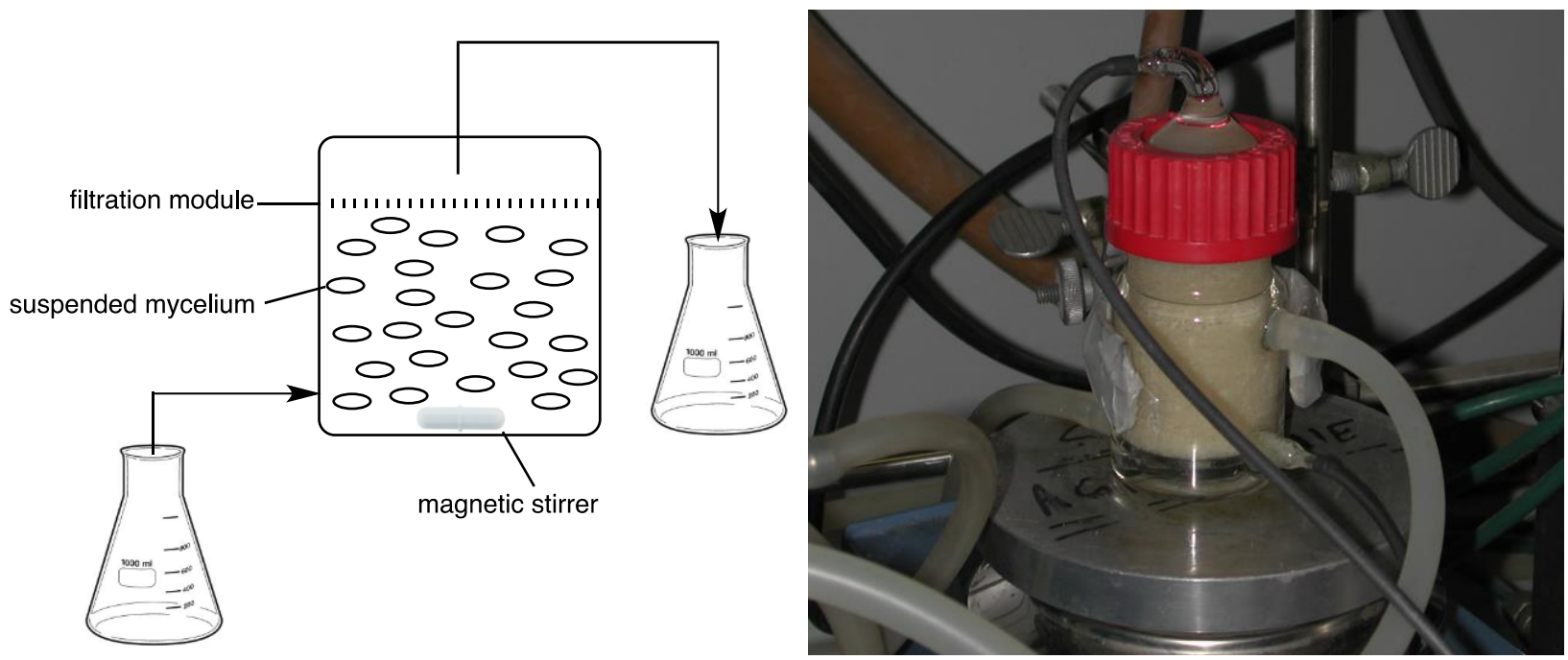

The temperature in the reactor was kept constant by circulating water in the jacket. A Gilson Miniplus 2 peristaltic pump controlled incoming liquid flow.

The molar balance for a continuous stirred tank reactor (CSTR) has the following expression, where $F_{A}$ stands for the molar flow rate of substrate:

$$
V=\frac{F_{A, \text { in }}-F_{A, \text { out }}}{\left(-r_{a}\right)}
$$

One can rewrite as: 


$$
\tau=\frac{C_{A o}-C_{A}}{\left(-r_{A}\right)} \quad \text { or } \quad \tau=\frac{C_{A o} X_{A}}{\left(-r_{A}\right)}
$$

Finally, rate of the CSTR was calculated using the algebraic equation 3 :

$$
r=\frac{C_{A o} X_{A}}{\tau}
$$

\subsection{Analysis}

Isoamyl alcohol and isoamyl acetate concentrations were determined by gaschromatographic $(\mathrm{GC})$ analysis by $\mathrm{GC}$ analysis on a Carlo Erba Fractovap GC equipped with a fused-silica capillary column MEGA-DEX DMP-Beta (dimethyl pentyl- $\beta$-cyclodextrin, $25 \mathrm{~m} \times 0.25 \mathrm{~mm}$ i.d.), with the injector temperature at $200^{\circ} \mathrm{C}$. Oven temperature was a 5 ${ }^{\circ} \mathrm{C} / \mathrm{min}$ gradient from 40 to $180{ }^{\circ} \mathrm{C}$. The retention times were: isoamyl alcohol, $6.7 \mathrm{~min}$; isoamyl acetate, $7.1 \mathrm{~min}$. Cinnamyl alcohol and cinnamyl acetate concentrations were determined with a fused-silica capillary column MEGA-SE30 (100\% methyl polysiloxane; 25 $\mathrm{m} \times 0.25 \mathrm{~mm}$ i.d.), with the injector temperature at $200^{\circ} \mathrm{C}$. Oven temperature was $80^{\circ} \mathrm{C}(2$ minutes) and then from 80 to $180{ }^{\circ} \mathrm{C}$ with a $5{ }^{\circ} \mathrm{C} / \mathrm{min}$ gradient. The retention times were: cinnamyl alcohol, $9.9 \mathrm{~min}$; cinnamyl acetate, $13.2 \mathrm{~min}$.

\section{RESULTS AND DISCUSSION}

\subsection{Isoamyl acetate preparation: optimization of batch reaction}

Direct esterification of isoamyl alcohol with acetic acid in $n$-heptane for the preparation of isoamyl acetate was firstly carried out in batch mode using dry mycelium of Aspergillus oryzae. Isoamyl acetate is used as a flavouring compound, having a characteristic banana flavour property. ${ }^{1}$ Optimization of the biotransformation was accomplished by sequential experimental trials using a Multisimplex® 2.0 software, previously employed for the optimization of biotransformations. ${ }^{33}$ Response variables were the productivity of the biotransformation (defined as amount of product per amount of biocatalyst per unit of time) and the molar conversion of the alcohol, both determined after $24 \mathrm{~h}$; the control variables were alcohol concentration, biocatalysts concentration, molar ratio (acid/alcohol), and temperature. The initial levels considered for the optimization are listed in Table 1.

\begin{tabular}{|l|c|c|c|c|}
\hline & \multicolumn{3}{|c|}{ Control variables } \\
\hline & Alcohol $(\mathrm{mM})$ & Dry mycelium $(\mathrm{mg} / \mathrm{mL})$ & Molar ratio & $\mathrm{T}\left({ }^{\circ} \mathrm{C}\right)$ \\
\hline
\end{tabular}




\begin{tabular}{|c|c|c|c|c|}
\hline Reference value & 25 & 20 & 1.5 & 40 \\
\hline Step size & 5 & 5 & 0.2 & 5 \\
\hline Minimum & 10 & 5 & 1.0 & 20 \\
\hline Maximum & 200 & 40 & 3.0 & 70 \\
\hline
\end{tabular}

Table 1. Control variables and initial levels considered for the optimization of the esterification between isoamyl alcohol and acetic acid catalysed by mycelium-bound lipase of Aspergilllus oryzae.

The results of the sequential experiments aimed at the optimization of the bioconversion are shown in Fig. 1. Each trial was performed in triplicate and the mean value was introduced as response for further optimization.

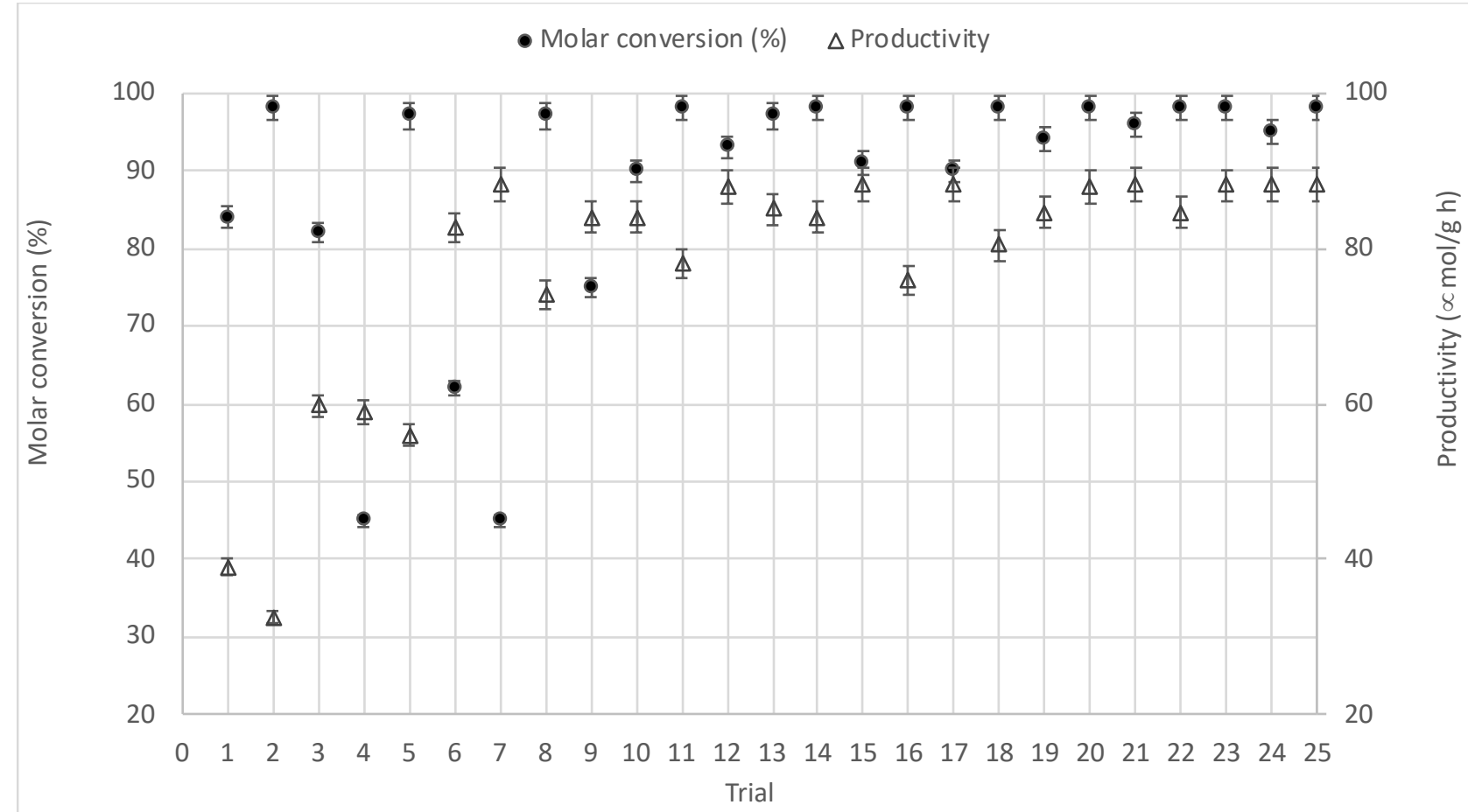

Figure 2. Sequential optimization of the esterification between isoamyl alcohol and acetic acid catalysed by mycelium-bound lipase of Aspergilllus oryzae. Experimental responses ( $\triangle$ productivity; $\bullet$ molar conversion) are reported as function of sequential trials. Values represent the mean of separate assays in triplicate.

The highest molar conversion (98\%) and overall productivity $\left(88.2 \mu \mathrm{mol} \mathrm{g}^{-1} \mathrm{~h}^{-1}\right)$ were simultaneously met in trials 20,23 , and 25 ; conditions corresponding to the trial 25 (isoamyl alcohol $=54 \mathrm{mM}$, dry mycelium $=25 \mathrm{mg} \mathrm{mL}^{-1}$, molar ratio acid/alcohol $1.2 / 1$ at $50{ }^{\circ} \mathrm{C}$ ) were chosen for further experiments, since the lowest amount of biocatalyst still gave the highest 
amount of isoamyl acetate. Figure 3 reports the time-course of the direct esterification of isoamyl alcohol with acetic acid under the optimised conditions.

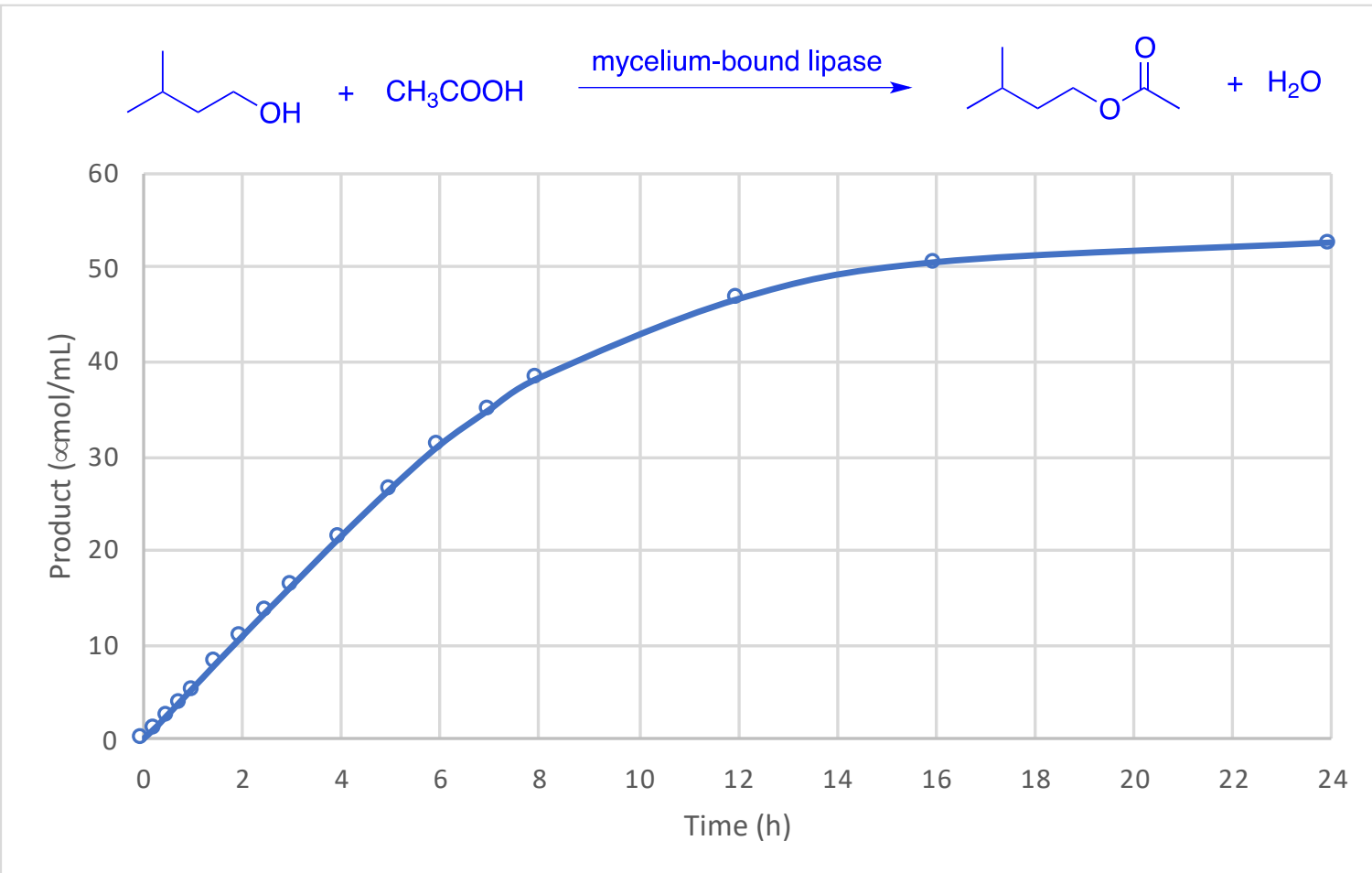

Figure 3. Esterification between isoamyl alcohol and acetic acid catalysed by mycelium-bound lipase from A. oryzae. Reaction conditions: initial alcohol concentration $54 \mathrm{mM}$; initial acetic acid concentration $65 \mathrm{mM}$ in $n$-heptane containing $25 \mathrm{~g} \mathrm{~L}^{-1}$ of biocatalyst at $50^{\circ} \mathrm{C}$. Results are the mean of three replicates.

The reaction occurred with high yield in $24 \mathrm{~h}$ with a reaction rate was quite constant in the first 3 hours $(0.089 \mu \mathrm{mol} / \mathrm{mL} \mathrm{min})$.

\subsection{Isoamyl acetate preparation: optimization of continuous reactor}

The encouraging results obtained in batch reactions led us to explore the possibility to carry out continuous biotransformations in a continuous stirred tank membrane reactor (CST-MR), where mixing of the heterogeneous system should be optimal. The continuous stirred tank membrane reactor (CST-MR) described in details in the Material section (50 mL working volume) was employed for continuous operations; the biocatalyst was retained in the reactor by an ultrafiltration membrane, which allowed for permeation of the outflow solution.

The CST-MR was packed with a suspension of dry mycelium (1.25 g, corresponding to 25 $\mathrm{g} \mathrm{L}^{-1}$ ) in $n$-heptane and the solvent was flown in a recirculation mode for 72 hours at a flow rate $(Q)$ of $0.2 \mathrm{ml} \mathrm{min}^{-1}$, corresponding to a hydraulic residence time of $250 \mathrm{~min}$ (residence 
time: $\tau=V / Q$, where $V$ is the reactor volume and $Q$ is the flow rate). No filter plugging or release of enzymatic activity was observed during the time of the operation.

Direct esterification of isoamyl alcohol with acetic acid in CST-MR was then studied; substrates were continuously added in a $n$-heptane solution and the composition of the outflow solution monitored by GC. Experiments were initially focused to reach the best compromise between reaction rate and degree of conversion by applying different flow rates (Table 2).

\begin{tabular}{|c|c|c|c|c|c|}
\hline$Q(\mathrm{~mL} / \mathrm{min})$ & $\tau(\min )$ & $C_{\text {alcohol }}(\mathrm{mM})^{\mathrm{a}}$ & $F_{\text {alcohol }}(\mu \mathrm{mol} / \mathrm{min})$ & Conversion $(\%)$ & Rate $(\mu \mathrm{mol} / \mathrm{min})$ \\
\hline 0.10 & 500 & 50 & 5.0 & 83 & 0.083 \\
0.10 & 500 & 55 & 5.5 & 82 & 0,090 \\
0.10 & 500 & 60 & 6.0 & 78 & 0,094 \\
0.14 & 350 & 50 & 7.0 & 56 & 0.090 \\
\hline
\end{tabular}

Table 2. Optimization of the continuous esterification of isoamyl alcohol with acetic acid catalysed by mycelium-bound lipase from $A$. oryzae carried out in CST-MR. Initial stoichiometric ratio between acid/alcohol was always 1.2. alnitial alcohol concentration.

Experiments carried out with a $\tau=500$ min allowed for molar conversions in the range of $78-83 \%$, depending on the $F_{\text {alcohol }}$ in the inlet flow; the best compromise between conversion and rate was found with a $F_{\text {alcohol }}$ of $5.5 \mu \mathrm{mol} / \mathrm{min}$ (corresponding to a $C_{\text {alcohol }}=55 \mathrm{mM}$ and $C_{\text {acetic acid }}=66 \mathrm{mM}$ ) corresponding to a rate of $0.092 \mu \mathrm{mol} / \mathrm{min}$. The rate was slightly better than the one observed in batch reactor, showing the good performance in terms of mixing of the CST-MR. Experiments were also carried out at lower residence time $(t=350 \mathrm{~min})$, observing a significant decrease in the conversion.

\subsection{Isoamyl acetate preparation: stability of the biocatalyst in the continuous reactor}

The continuous operation aimed at the preparation of isoamyl acetate was carried out for 10 days under optimized conditions (inflow solution containing $55 \mathrm{mM}$ isoamyl alcohol and $65 \mathrm{mM}$ acetic acid, $\tau=500 \mathrm{~min}$ at $50^{\circ} \mathrm{C}$ ); no decrease of the molar conversion was observed at the end of the operation, indicating a notable operational stability of the catalyst. Table 3 summarizes the results of the continuous biotransformation over 10 days, which allowed for a remarkable overall reactor productivity (defined here as the amount of isoamyl acetate produced for volume of reactor) of $169 \mathrm{mg} \mathrm{ml}^{-1}$. 


\begin{tabular}{cccccc}
\hline $\begin{array}{c}Q \\
\left(\mathrm{~mL} \mathrm{~min}^{-1}\right)\end{array}$ & $\begin{array}{c}\tau \\
(\mathrm{min})\end{array}$ & $\begin{array}{c}\text { Conv. }^{\mathrm{a}} \\
(\%)\end{array}$ & $\begin{array}{c}\text { Space time yield } \\
\left(\mathrm{mmol} \mathrm{d}^{-1}\right)\end{array}$ & $\begin{array}{c}\text { Catalyst productivity } \\
\left(\mathrm{mmol} \mathrm{g}^{-1}\right)\end{array}$ & $\begin{array}{c}\text { Reactor productivity } \\
\left(\mathrm{mg} \mathrm{mL}^{-1}\right)\end{array}$ \\
\hline 0.10 & 500 & 82 & 6.49 & 51.95 & 169 \\
\hline
\end{tabular}

Table 3. Continuous esterification of isoamyl alcohol with acetic acid catalysed by mycelium-bound lipase from A. oryzae carried out in CST-MR for 10 days. ${ }^{a}$ Conversion detected in the exiting flow after 10 days of operation. ${ }^{b}$ Productivity is referred to the amount of ester formed after an operation time of 10 days

A closed-loop reactor was also set up by recirculating the outflowing solution; after $16 \mathrm{~h}$ of operation, the mycelium-bound lipase was able to catalyse a conversion of $98 \%$ of isoamyl alcohol into the corresponding acetate ester.

\subsection{Cinnamyl acetate preparation: batch and continuous reactor}

Biocatalytic preparation of cinnamyl acetate was also studied; cinnamyl acetate is characterised by a typical pineapple flavor. ${ }^{1}$ Direct acetylation of cinnamyl alcohol was accomplished applying the optimized conditions employed for the direct esterification of isoamyl alcohol. Figure 4 shows the time-course of the batch biotransformation.

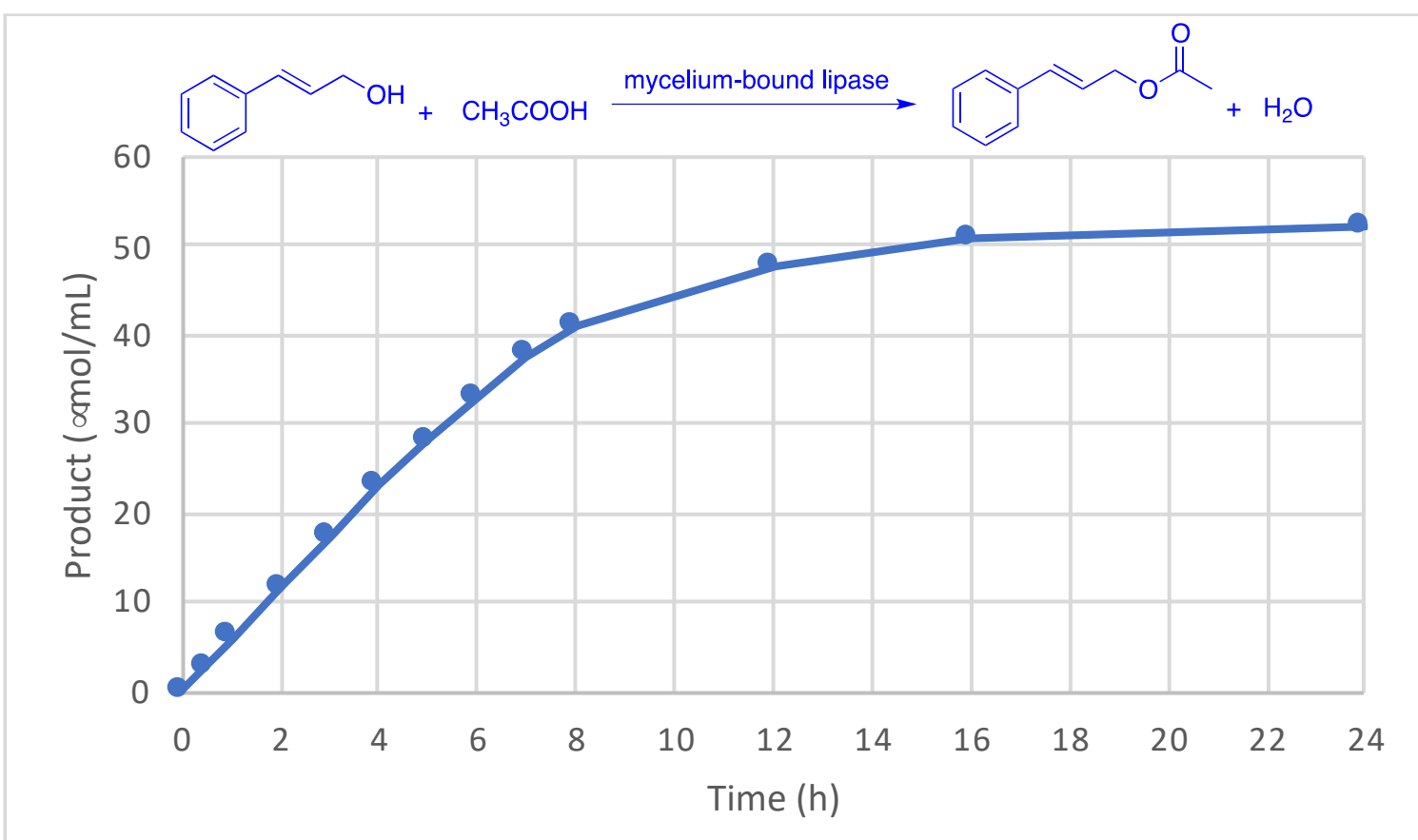

Figure 4. Esterification between cinnamyl alcohol and acetic acid catalysed by mycelium-bound lipase from $A$. oryzae. Reaction conditions: initial alcohol concentration $54 \mathrm{mM}$; initial acetic acid concentration $65 \mathrm{mM}$ in $n$-heptane containing $25 \mathrm{~g} \mathrm{~L}^{-1}$ of biocatalyst at $50^{\circ} \mathrm{C}$. Results are the mean of three replicates. 
The rate of acetylation of cinnamyl alcohol was slightly higher (steady reaction rate in the first 3 hours of $0.095 \mu \mathrm{mol} / \mathrm{mL} \min$ ) than what observed with isoamyl alcohol, whereas final conversion after $24 \mathrm{~h}$ was $95-96 \%$. Since acetylation of cinnamyl alcohol occurred with a time-course similar to what observed for isoamyl alcohol, continuous operation was carried out under the same conditions $\left(C_{\text {alcohol }}=55 \mathrm{mM}, F_{\text {alcohol }}=5.5 \mu \mathrm{mol} / \mathrm{min}, C_{\text {acid }}=66 \mathrm{mM}, Q=\right.$ $0.1 \mathrm{ml} \mathrm{min}^{-1}, \tau=500 \mathrm{~min}$ at $50^{\circ} \mathrm{C}$ ) and in the same CST-MR. Also, in this case, the biocatalyst was stable over 10 days of reaction; Table 4 summarizes the data of the continuous bioprocess.

\begin{tabular}{cccccc}
\hline $\begin{array}{c}Q \\
\left(\mathrm{~mL} \mathrm{~min}^{-1}\right)\end{array}$ & $\begin{array}{c}\tau \\
(\mathrm{min})\end{array}$ & $\begin{array}{c}\text { Conv. }^{\mathrm{a}} \\
(\%)\end{array}$ & $\begin{array}{c}\text { Space time yield } \\
\left(\mathrm{mmol} \mathrm{d}^{-1}\right)\end{array}$ & $\begin{array}{c}\text { Catalyst productivity }^{\mathrm{b}} \\
\left(\mathrm{mmol} \mathrm{g}^{-1}\right)\end{array}$ & $\begin{array}{c}\text { Reactor productivity }^{\mathrm{b}} \\
\left(\mathrm{mg} \mathrm{mL}^{-1}\right)\end{array}$ \\
\hline 0.10 & 500 & 80 & 6.34 & 50.69 & 223 \\
\hline
\end{tabular}

Table 4. Continuous esterification of cinnamyl alcohol with acetic acid catalysed by mycelium-bound lipase from $A$. oryzae carried out in CST-MR for 10 days. ${ }^{a}$ Conversion detected in the exiting flow after 10 days of operation. ${ }^{b}$ Productivity is referred to the amount of ester formed after an operation time of 10 days

\subsection{Conclusion}

The mycelium-bound lipase activity of Aspergillus oryzae was exploited for the direct esterification of isoamyl and cinnamyl alcohol with acetic acid for the preparation of the corresponding flavour-active esters is here reported. Remarkably, similar acetylation rates and molar conversions were observed, although two alcohols with quite different structure were employed. It is worthy to underline that the biotransformation occurred in $n$-heptane without any particular system for the removal of the water produced; it has previously suggested that the mycelia supply a hydrophobic micro-environment, thus disfavouring water access to the enzymes which catalyse the reaction. ${ }^{34} \mathrm{~A}$ stirred tank membrane reactor (CST-MR) was set up for carrying out continuous biotransformations; reusability of the biocatalyst reduce the cost of fermentation, necessary for its production. Indeed, the CSTMR guaranteed at least 10 days of operation without any significant loss of the biocatalyst activity; reactor productivity (defined as the amount of ester formed per volume of reactor) was $169 \mathrm{mg} / \mathrm{mL}$ for isoamyl acetate and $223 \mathrm{mg} / \mathrm{mL}$ for cinnamyl acetate.

In conclusion, a highly effective continuous production of flavour-active acetate esters was obtained with dry mycelium, without any necessity of costly or laborious enzymatic purification, and without the need of water sorption during the prolonged bioprocess. 


\section{REFERENCES}

1 Burdock, GA. (2010). Fenaroli's handbook of flavor ingredients (6th ed.). Boca Raton, CRC Press.

2 Dhake KP, Thakare DD, Bhanage BM. Lipase: A potential biocatalyst for the synthesis of valuable flavour and fragrance ester compounds. Flavour Fragr. J. 2013;28:71-83.

3 Ferreira-Dias S, Sandoval G, Plou F, Valero F. The potential use of lipases in the production of fatty acid derivatives for the food and nutraceutical industries. Electron. J. Biotechnol. 2013;16.

4 Sa, AGA, de Meneses AC, de Arauujo PHH, de Oliveira D. A review on enzymatic synthesis of aromatic esters used as flavor ingredients for food, cosmetics and pharmaceuticals industries. Trends Food Sci. Technol. 2017;69:95-105.

5 Mathews I, Soltis M, Saldajeno M, Ganshaw G, Sala R, Weyler W, Cervin MA, Whited $\mathrm{G}$, Bott R. Structure of a novel enzyme that catalyzes acyl transfer to alcohols in aqueous conditions. Biochemistry 2007;46:8969-8979.

6 Wiermans L, Hofzumahaus S, Schotten C, Weigand L, Schallmey M, Schallmey A, Domıńguez de Maria P. Transesterifications and peracid-assisted oxidations in aqueous media catalyzed by Mycobacterium smegmatis acyl transferase. ChemCatChem 2013;5:3719-3724.

7 Chiarelli Perdomo I, Gianolio S, Pinto A, Romano D, Contente ML, Paradisi F, Molinari F. J. Agric. Food Chem., 2019;67:6517-6522.

8 Halling PJ. Solvent selection for biocatalysis in mainly organic systems: Predictions of effects on equilibrium position. Biotechnol. Bioeng. 1990;35:691-701.

9 Klibanov AM. Improving enzymes by using them in organic solvents. Nature 2001;409:241-246.

10 Spizzo P, Basso A, Ebert C, Gardossi L, Ferrario V, Romano D, Molinari F. Resolution of $(R, S)$-flurbiprofen catalysed by dry mycelia in organic solvent. Tetrahedron 2007;63:11005-11010.

11 Gubicza L, Kabiri-Badr A, Keoves E, Belafi-Bako K. Large-scale enzymatic production of natural flavour esters in organic solvent with continuous water removal. J. Biotechnol. 2000;84:193-196.

12 De Castro HF, De Oliveira PC, Pereira EB. Evaluation of different approaches for lipase catalysed synthesis of citronellyl acetate. Biotechnol. Lett. 1997;19:229-232.

13 Güvenç A, Kapucu N, Mehmetoglu U. The production of isoamyl acetate using immobilized lipases in a solvent-free system. Proc. Biochem. 2002;38:379-386. 
14 Melo LLMM, Pastore GM, Macedo GA. Optimized synthesis of citronellyl flavour esters using free and immobilized lipase from Rhizopus sp. Proc. Biochem. 2005;40:31813185.

15 Romero MD, Calvo L, Alba C, Daneshfar A, Ghaziaskar HS. Enzymatic synthesis of isoamyl acetate with immobilized Candida antarctica lipase in $n$-hexane. Enzyme Microb. Technol. 2005;37:42-48.

16 Karra-Châabouni M, Ghamgui H, Bezzine S, Rekik A, Gargouri Y. Production of flavour esters by immobilized Staphylococcus simulans lipase in a solvent-free system Proc. Biochem. 2006;41:1692-1698.

17 Ozyilmaz G, Gezer E. Production of aroma esters by immobilized Candida rugosa and porcine pancreatic lipase into calcium alginate gel. J. Mol. Catal. B: Enzymatic 2010;64:140-145.

18 Martins AB, Graebin NG, Lorenzoni ASG, Fernandez-Lafuente R, Ayub MAZ, Rodrigues RC. Rapid and high yields of synthesis of butyl acetate catalyzed by Novozym 435: Reaction optimization by response surface methodology. Proc. Biochem. 2011;46:23112316.

19 Matte CR, Bordinhão C, Poppe JK, Rodrigues RC, Hertz PF, Ayub MAZ. Synthesis of butyl butyrate in batch and continuous enzymatic reactors using Thermomyces lanuginosus lipase immobilized in Immobead 150. J. Mol. Catal. B: Enzymatic 2016;127:67-75.

20 Gomes Almeida Sá A, de Meneses AC, Lerin LA, de Araújo PHH, Sayer C, de Oliveira $D$. Biocatalysis of aromatic benzyl-propionate ester by different immobilized lipases. Bioproc. Biosyst. Eng. 2018;41:585-591.

21 Tamborini L, Romano D, Pinto A, Bertolani A, Molinari F, Conti P. J. Mol. Catal. B: Enzym. 2012;84:78-82.

22 Itabaiana I, de Mariz e Miranda LS, de Souza ROMA. J. Mol. Catal. B: Enzym. 2013;85$86: 1-9$.

23 Carvalho CML, Aires-Barros MR, Cabral JMS. A continuous membrane bioreactor for ester synthesis in organic media: II. Modeling of MBR continuous operation. Biotechnol. Bioeng. 2001;72:136-143.

24 Trusek-Holownia A, Noworyta A. An integrated process: Ester synthesis in an enzymatic membrane reactor and water sorption. J. Biotechnol. 2007;130:47-56.

25 Damnjanovic JJ, Zuza MG, Savanovic JK, Bezbradica DI, Mijin DZ, Boskovic-Vragolovic N, Knezevic-Jugovic ZD. Covalently immobilized lipase catalyzing high-yielding 
optimized geranyl butyrate synthesis in a batch and fluidized bed reactor. J. Mol. Catal. B: Enzymatic 2012;75:50-59.

26 Giovannini PP, Catani M, Massi A, Sacchetti G, Tacchini M, deOliveira D, Lerin LA. Continuous production of eugenol esters using enzymatic packed-bed microreactors and an evaluation of the products as antifungal agents. Flavour Fragr J. 2019;34:201210.

27 Novak U, Lavric D, Žnidaršič-Plaz P. Continuous Lipase B-catalyzed isoamyl acetate synthesis in a two-liquid phase system using Corning® AFRTM module coupled with a membrane separator enabling biocatalyst recycle. J. Flow Chem. 2016;6:33-38.

28 Molinari F, Marianelli G, Aragozzini F. Production of flavour esters by Rhizopus oryzae. Appl. Microbiol. Biotechnol. 1995;43:967-973.

29 Zambelli P, Fernandez-Arrojo L, Romano D, Santos-Moriano D, Gimeno-Perez M, Poveda A, Gandolfi R, Fernández-Lobato M, Molinari F, Plou FJ. Production of fructooligosaccharides by mycelium-bound transfructosylation activity present in Cladosporium cladosporioides and Penicilium sizovae. Proc. Biochem. 2014;49:21742180.

30 Zambelli P, Serra I, Fernandez-Arrojo L, Plou FJ, Tamborini L, Conti P, Contente ML, Molinari F, Romano D. Sweet-and-salty biocatalysis: Fructooligosaccharides production using Cladosporium cladosporioides in seawater Proc. Biochem. 2015;50:1086-1090.

31 Gandolfi R, Converti A, Pirozzi D, Molinari F. Efficient and selective microbial esterification with dry mycelium of Rhizopus oryzae. J. Biotechnol. 2001;92:21-26.

32 Tamborini L, Romano D, Pinto A, Contente M, lannuzzi MC, Conti P, Molinari F. Biotransformation with whole microbial systems in a continuous flow reactor: resolution of (RS)-flurbiprofen using Aspergillus oryzae by direct esterification with ethanol in organic solvent. Tetrahedron Lett. 2013;54:6090-6093.

33 Contente ML, Molinari F, Zambelli P, De Vitis V, Gandolfi R, Pinto A, Romano D. Biotransformation of aromatic ketones and ketoesters with the non-conventional yeast Pichia glucozyma. Tetrahedron Lett. 2014;55:7051-7053.

34 Converti A, Gandolfi R, Zilli M, Molinari F, Binaghi L, Perego P, Del Borghi M. Synthesis of ethyl phenylacetate by lyophilized mycelium of Aspergillus oryzae. Appl Microbiol Biotechnol 2005;67:637-640. 